\title{
Metaphor in ApPlied Linguistics: Four Cognitive Approaches
}

(A Metáfora na Lingüística Aplicada: Quatro Abordagens Cognitivas)

Gerard STEEN

(Department of English Language and Culture.

Vrije Universiteit; The Netherlands)

ABSTRACT: This article presents some considerations into metaphor in language and thought- 'the topic and title of the first conference of its kind in Brazil'. The paper focuses on the discussions presented in the round table, which were mostly directed to the empirical research on metaphor in Applied Linguistics. This integrative and retrospective reflection on the papers presented will be conducted from the perspective of the debate into the relationship between metaphor in language and in thought. This central issue is at the core of my proposal for four different approaches to metaphor, based on the interdependence between language and thought as system and as use:1) metaphor in language as system; 2) metaphor in thought as system; 3) metaphor in language as use and 4) metaphor in thought as use. It is within the framework of these categories that metaphors should be studied, with a certain degree of autonomy, so that their interdependence can be better understood.

KEY-WORDS: the study of metaphor in Applied Linguistics; different cognitive approaches; metaphor in language as system; metaphor in language as use; metaphor in thought as system; metaphor in thougt as use.

RESUMO: Este artigo apresenta algumas considerações sobre a metáfora na língua e no pensamento - "o tópico e título da primeira conferência desse tipo no Brasil". Focaliza as discussões apresentadas nas falas da plenária, que são principalmente direcionadas para a pesquisa empírica sobre metáfora na Lingüística Aplicada. Esta reflexão retrospectiva que integra os trabalhos apresentados é conduzida a partir da perspectiva do debate sobre a relação entre metáfora na língua e no pensamento. Esta questão é central na minha proposta de quatro diferentes abordagens da metáfora, com base na interdependência entre língua e pensamento como sistema e como uso: 1) metáfora na língua como sistema; 2) metáfora no pensamento como sistema; 3) metáfora na língua

D.E.L.T.A., 22:EsPECIAL, 2006 (21-44) 
em uso; 4) metáfora no pensamento em uso. A metáfora deveria ser estudada a partir dessas categorias, com um certo grau de autonomia, de modo que as sua interdependência possa ser melhor entendida.

PALAVRAS-CHAVE: o estudo da metáfora na Lingüística Aplicada; diferentes abordagens cognitivas; a metáfora na língua como sistema; a metáfora na língua em uso; a metáfora no pensamento como sistema; a metáfora no pensamento em uso.

\section{Four cognitive approaches to metaphor}

It is my privilege to offer some integrative and prospective remarks about "metaphor in language and thought", the topic and title of the first conference of its kind in Brazil. When I was originally preparing for this task, I did so from the perspective of the book I am currently writing with Ray Gibbs, entitled Finding metaphor in language and thought (Steen and Gibbs in preparation). The tentative structure of our book formed the guideline for the series of workshops we offered during the conference, and it was my intention for the present contribution to review the main claims we had been making. However, the continued high-quality discussions at the conference itself have made it unnecessary to go over these grounds again. What I will do instead, therefore, is make a connection with the main concern of most of the participants at the conference, doing empirical metaphor research in applied linguistics.

The conference organization lying in the hands of Mara Sofia Zanotto and her colleagues from LAEL at PUC São Paulo, it is no surprise that applied linguistics turned out to be the focus of discussion. The presence of Lynne Cameron and Jacob Mey as other keynote speakers only reinforced this tendency. That is why I will make some comments about metaphor in applied linguistics from my more general concern with metaphor in language and thought.

Only fairly recently have students of metaphor been joined by applied linguists. The collection of chapters edited by Cameron and Low (1999a) is the most important testimony to this development. It is the first book publication coming out of a series of originally applied-linguistics conferences called "Researching and applying metaphor", or RAAM, which was founded by Cameron and Low. Other results of this conference series 
may be encountered in Metaphor and Symbol (Volume 14, Number 1, 1999) and Journal of Pragmatics (Steen in press). More metaphor research of an applied linguistic nature has been reviewed by Cameron and Low (1999b).

When applied linguists study metaphor, they are typically concerned with metaphor in language as use (e.g. Cameron and Low 1999a: xiii; Low and Cameron 2002: 84). This includes ordinary discourse (any kind of communication by means of language, typically in some institutional context), language learning and language teaching of various kinds, and more general practices of language counseling and advice, such as text design. Part of this endeavor, moreover, is concerned with intervening in language use: as Cameron has claimed, linguistics is applied not just to describe the world of language use, but to change it.

These comments leave a lot of overlap between applied linguistics and discourse analysis, which I think is as it should be. There are important differences between these two areas of study too, especially when it comes to applying knowledge of language and discourse in practice, such as education, communication, and so on. But I think these issues are ultimately irrelevant to the purposes of the present paper.

However, these observations are meaningless unless we know what does not qualify as "language as use". I propose that language as use ought to be contrasted with language as system, and that language itself ought to be differentiated from thought. The complete set of cognitive approaches to metaphor, then, consisting of combinations of single perspectives, looks like this:

- metaphor in language as system

- metaphor in thought as system

- metaphor in language as use

- metaphor in thought as use

Even though some scholars may be worried about the artificiality of these distinctions, I think that it is useful to explore them, simply because many linguists keep making an appeal to different combinations of them (approaches) when they characterize their own practice. Thus, the same distinctions may be recognized in Cameron and Low's (1999a) preface describing the general field of metaphor studies. Ray Gibbs (1999a), in his analysis of the experience of literal and figurative meaning (language and 
thought as use), treats intentions as more important than the meanings of words or utterances themselves. George Lakoff (1994) has written about conceptual systems as related to cognitive processing as well as to linguistic systems and their use. And Ray Jackendoff s (2002) new addition to the development of a conceptual semantics shows that these distinctions are important for non cognitive-linguistic work on meaning outside metaphor and applied linguistics, too. As long as it is recalled that these are distinct perspectives on language and thought, not hard-and-fast distinctions between language and thought themselves, it may be useful to differentiate between these approaches as diverging ways of conceptualizing the object of study.

Various disciplines have made contributions to each of these approaches. Cognitive linguistics is involved in all of them, whereas applied linguistics is mostly concerned with the third and fourth approaches, as is, for instance, discourse analysis. One reason for distinguishing between approaches as opposed to disciplines is that disciplines may include more than one approach whereas it is essential for some purposes to be precise about which approach one is taking. This also enables researchers to combine aspects from more than one discipline (e.g. applied linguistics, discourse analysis, pragmatics, and cognitive linguistics) for the purposes of pursuing just one approach (e.g. metaphor in language as use).

The more positive definition of language as use is no trivial matter, as may be gleaned from the various definitions of discourse discussed by Schiffrin, Tannen, and Hamilton (2001) in their Handbook of discourse analysis. Moreover, any empirical approach to language use, I would argue, cannot ignore the cognitive and social role of discourse genres as a means for managing and monitoring the many aspects of language use, including metaphorical language use (Steen 1999; 2002a; 2002b). Genre functions as an explanatory concept for many aspects of metaphor in language use, but the notion of genre itself is no simple definitional matter either. And finally there is the problem of the definition of metaphor as opposed to non-metaphor in language as use. Cameron (1999b: 114) has discussed several criteria for defining and especially identifying metaphor in language use, and they can produce rather different results regarding what counts as a metaphorical stretch of language.

There are hence at least three fundamental theoretical problems in any applied-linguistic study of metaphor: 
- the definition of language as use

- the definition of genre as a cognitive or social device for monitoring language use

- the definition of metaphor in language as use

The fourfold distinction between cognitive approaches to metaphor may now be used to discuss the definition of language as use. In making a distinction between the four approaches, I would like to suggest that it is possible and even useful to adopt a restricted approach to language as language use, by momentarily backgrounding language as system, or backgrounding thought as conceptual system and its use. Let me begin with an illustration.

Cameron (1999b: 114) suggests that salary "can be said to be metaphorical because it originally referred to salt given to Roman soldiers". What I would like to argue is that this fact is irrelevant to the study of language as use, simply because very few contemporary language users have access to this fact. What is more, I suggest that applied linguists should ignore it for the study of language as use while at the same time admitting that, for other purposes, salary may have to be regarded as metaphorical or metonymic in approaching language as a (diachronic) system (e.g. Geeraerts 1997). Thus, salary may be figurative in one approach (language as system) whereas it may be literal in another approach (language as use).

Applied linguists do not have to take everything on board that has come out of other approaches to metaphor, because some of these findings may simply be irrelevant to their approach of metaphor given their conceptualization of language as use. However, by the same token it may be perfectly possible for applied linguists to utilize other information about metaphor that has come from work done in other approaches that is relevant for the study of metaphor in language use. Thus, much of the cognitivelinguistic work on metaphor in language and thought may be said to embody an approach to language as system, especially a lexical system, and thought as system, especially a conceptual system. It would be obnoxious for the study of metaphor in language use to ignore all findings from these lines of research. In fact, it has been precisely these findings which have now triggered an interest in their application in applied linguistics, which studies the use of these systems in actual discourse. As a 
result, many of the findings of these other approaches have to be taken seriously in the study of metaphor in language use and play the role of assumed background knowledge in applied-linguistic research. I will offer one or two illustrations in a moment.

This is the point of making and using the distinctions introduced above. A bird's eye view of the study of metaphor shows that applied linguists momentarily assume some status quo in general and cognitive linguistics (regarding language as system) and cognitive linguistics (regarding thought as system). True, this is a status quo that applied linguists have to reconstruct for their own purposes, but they have to do so with maximal respect for the original approaches. The selection and organization of that status quo then facilitates examination of how parts of these two postulated systems affect the on-going use of metaphorical language in concrete situations of discourse. This is part of the excitement of doing this type of interdisciplinary research.

It may not be too difficult to accept such a picture of the division of labor for the three approaches mentioned just now. However, it may be a little harder for some to agree to the claim that if applied linguists focus on metaphor in language as use, they should also momentarily take for granted what is known about metaphor in thought as use. Many applied linguists (as well as discourse analysts, pragmaticians, and cognitive linguists) study the use of the language system and the use of the conceptual system in combination with each other, since they often deal with language use as an expression of more encompassing cognitive processes and social interaction. Cameron's starting point for her workshops at the conference, that "metaphors indicate understandings and attitudes," is a perfect illustration. However, I would like to insist that this still presupposes a careful distinction between, on the one hand, (linguistic) "metaphor," and, on the other hand, "understandings and attitudes" (thought). Otherwise it would be hard to examine their relation in a controlled fashion.

I would therefore like to advocate the same argument as above, and suggest that we see the approach of metaphorical thought-as-process (or use of a conceptual system) as one distinct approach to doing empirical metaphor research, even when we examine metaphor in language use. And when we do look at metaphorical thought as a process in its own terms, we need to take on board not just the work done in cognitive linguistics, but the complete tradition of psycholinguistics and cognitive and social psychology, as well as the many useful distinctions and findings it has 
produced. We have to assume (or construct) some state of play in that tradition in the same way as we do for general linguistics and cognitive linguistics with respect to language as system and thought as system, respectively. As Cameron (1999a: 12-13) has noted, "Theoretical clarity is also needed in the relation assumed between [my emphasis, GS] language and thought, as this will underlie inferences that are made between linguistic evidence and thinking."

For instance, when applied linguists make assumptions about metaphor as thought, they have to be aware of such processing distinctions as those proposed by Gibbs (1994), between comprehension and subsequent processing of the product of comprehension, as in recognition, interpretation, and appreciation (cf. Gibbs 1999b). Comprehension refers to the thought process concerned with the immediate appropriation of an utterance by an addressee, until the point of the utterance is understood. This is often referred to as the "click of comprehension." However, after this first moment of comprehension, people may continue to process the mental product of this comprehension process and think about the utterance as a metaphor (metaphor recognition), or assign an evaluation to the effort they have had to put into comprehending and perhaps interpreting it (metaphor appreciation). My own work on metaphor understanding in literature is concerned with these 'later' thought processes of recognition, interpretation, and appreciation (Steen 1994), and any conclusion about these optional late processes should not be confused with information about obligatory comprehension processes.

Applied linguists also need to be aware of three radically different operations that are possible for metaphor processing in natural discourse (Steen 1994):

- disambiguation of polysemy that is historically motivated by metaphor

- retrieval of a pre-stored metaphorical mapping

- on-line construction of a metaphorical mapping

The first scenario, for instance, makes it possible for an applied linguist to observe that a metaphor may be present in the language used, but that it does not have to be there in the on-line cognitive process of the language user (parts of the conceptual system used). 
Moreover, these forms of metaphor processing need to be distinguished from metaphoric processing. Metaphoric processing is a mode of cognition that is not dependent on the presence of linguistic metaphors in discourse per se but on some other conventions of a genre (Steen 1994; Gibbs 1999b). Looking at metaphor as thought hence includes people's construction of metaphoric cognitive representations for literary allegories or perhaps scientific or educational models, which are text genres that many scholars would say do not contain metaphoric language. Again, one approach does not lead to the same ordering of the study of metaphor as another approach.

We have also emphasized that different individuals may exhibit the various cognitive operations of metaphor processing in varying degrees (cf. Steen and Gibbs 1999). For instance, children may acquire some conceptual metaphors wholesale from their language learning without necessarily having to re-experience all the cultural and embodied events that originally gave rise to conceptual metaphors. Moreover, Gibbs (1999c) has argued that this may be a phenomenon that concerns every individual's relation to all of the metaphorical cultural patterns they participate in.

Applied linguists also have to take into account that, within individuals, cognitive processing of metaphorical language may take place at different levels of semantic depth and detail. Some processes require longer and deeper chains of cognitive operations on metaphorical expressions than others (Steen 2001). Thus, if metaphorical thought is defined as people's performing a complete mental mapping across domains, it may not be clear whether language users may also be said to think metaphorically if they only construct some kind of metaphorical proposition, or some comparison statement, or an analogy, and leave it at that. Again, the presence of metaphorical language in use does not lead in a direct fashion to a clear-cut situation regarding metaphorical thought in cognitive processing. Metaphorical talk does not necessarily equal metaphorical thought.

It is true that applied linguists need not limit their attention to metaphor in language as use, but may also be concerned with metaphor in cognitive processes, or with metaphor in cognitive processes plus metaphor in language use. Cameron (1999a: 8) has made a similar observation: "Researchers need to decide early in the process whether metaphor is being considered as a phenomenon of language, or of thought, or both, ..." 
However, I believe that applied linguists always need to study the language as use in order to arrive at an examination of thought as process (or its products) if they want to study that (too). That is the reason I have emphasized the role of metaphor in language as use.

The advantage of adopting the systematic distinctions between the four approaches to metaphor in language and thought is the following. Researchers do not have to feel that they are inconsistent when, for their own purposes, something does not count as metaphorical whereas for other purposes it does. I have exemplified this in various ways, concerning salary, polysemy disambiguation, and metaphorical thought by means of metaphoric processing, or by means of comparison or analogy. What is more, applied linguists do not have to feel that their approach should be able to deal with all of the issues of metaphor research from their intentionally limited and focused standpoint. There is a decided benefit in saying that some research operates with one approach whereas other research operates with a different approach: it may and hopefully will eventually be possible to see these approaches as complementary. Distinct approaches investigate a multidimensional object from different sides and consequently see the object from a different angle. The bird's eye view of science will then be able to integrate these approaches into one whole.

However, this picture also suggests that this will only be possible if researchers are willing to adopt related distinctions of the field, according to for instance language and thought as well as system and use, as I am suggesting. Moreover, they should also be willing to adopt consistent definitions for the phenomenon under study across the four approaches, the third fundamental problem for any applied- linguistic study of metaphor that I mentioned above. For instance, many students of metaphor today regard it as a case of non-literal mapping across conceptual domains (Lakoff 1993; Lakoff and Johnson 1999). As soon as this definition is shifted, either in the direction of blending theory (Fauconnier and Turner 2002; cf. Grady et al. 1999) or in the direction of class-inclusion theory (Glucksberg 2001; Glucksberg and Keysar 1993), this has implications for the definitions and their applications, in all four approaches. Working with a systematic distinction between these approaches facilitates the precise discussion of these shifts and implications for different research projects. 
In sum, the general nature of the cognitive approach to metaphor I am advocating resides in the assumption that language and thought are two related forms of cognition which need to be studied in their own terms in order to establish the precise nature of their relationship. Their study also has different shapes depending on whether they are seen as systems or as the use of those systems. This situation makes it possible to distinguish between four relatively autonomous approaches to metaphor as cognition.

The main property of the generally cognitive approach to metaphor is the move away from the emphasis on linguistic autonomy that has traditionally characterized much work in linguistics and pragmatics. We would like to endorse the novel claim and research program in cognitive linguistics that assumes and explores the interdependence between language and thought as system and use (Steen and Gibbs 1999). However, I also feel that this program has tended to obscure some of the real distinctions of metaphor in cognition by conflating the four approaches too much. For instance, it is not always clear whether the cognitive-linguistic claim that we understand love in terms of a journey applies to our generalized conceptual system or to a concrete on-line process of cognition. That is why we wish to use the distinctions between the approaches in order to examine their interrelations in a more precise and controlled fashion. This strategy assumes that we can offer provisional definitions of each of the four approaches - which is what I have attempted to do in a sketchy fashion - in order to facilitate the research into the relationships between the approaches afterwards. The next section will demonstrate how this cognitive approach to metaphor may help address some of the questions raised by the papers presented at the conference.

\section{Metaphor in language and thought}

When we adopt the cognitive approach to metaphor outlined above, we can see that the papers at the conference on metaphor in language and thought can be grouped together in various ways as a reflection of their close relation to one approach or another. In what follows, I will restrict my attention to the plenary papers and the symposia. I am not doing this because the other papers were inferior, because they were not; but simply because the general papers were accessible to everybody. 


\subsection{Philosophical approaches}

One general characteristic of the cognitive approach is its scientific as opposed to philosophical nature. True, the cognitive approach does have implications for philosophy, as has been pointed out by Lakoff and Johnson (1999). However, it is not inherently tied to a particular philosophy of the world, knowledge, or scientific knowledge itself. Lakoff and Johnson (1980; 1999) have argued for a close relationship between the cognitive approach to metaphor and their philosophy called "experientialism", which includes "embodied realism" as its epistemology. However, there are many researchers working in cognitive science who do not subscribe to this particular brand of philosophy. It is therefore of fundamental importance to keep these philosophical discussions alive, as was also demonstrated by the papers by Helena Martins as well as by Kanavillil Rajagopalan.

Rajagopalan raised the issue of the literalization of metaphor, and presented the claim that metaphor and literalness themselves are metaphorical notions. I wonder whether he is referring to the same notion of literalness as Lakoff (1986) or Gibbs (1993) here, who do not believe that there is a metaphorical element in their definitions, but that is just an aside. The interesting issue for the applied linguist, or for the cognitive researcher of metaphor in general, is the question how Rajagopalan's discussion has a bearing on doing empirical cognitive research. For even though there may be fundamental problems with the notion of literalness or metaphor, these problems have not led to an overall rejection of the notions themselves. The practical goal of doing research into metaphor, including its fundamentally problematic aspects, requires that one cuts the knot at a particular moment in order to get going with the empirical work.

What this means for the applied linguist is that researchers should not continue to hesitate forever in actually cutting the knot-an injunction which emphasizes the difference between the cognitive-scientific approach and the philosophical one. However, what this also means is that applied linguists should always be prepared to go back to the moment when they did cut the knot, in order to re-examine the assumptions they made in distinguishing between metaphor and non-metaphor, including literal, language and thought. It is one job of philosophers to keep asking questions about these assumptions and act as kind of academic hecklers. Turning the perspective round, however, it is the job of applied linguists and other 
empirical researchers to gather evidence that has a bearing on these questions, so that we do not keep going round in circles. This is precisely what the Pragglejaz metaphor identification project attempts to do in terms of theoretical and operational definitions for metaphor identification (Steen 2002c).

Helena Martins drew our attention to the widespread cognitivelinguistic assumption that metaphors are based in relatively stable and established conceptual systems, the thought-as-system approach I distinguished above. She discussed how this approach affects our view of metaphor novelty or conventionality, making novel metaphor "a possible but relatively rare phenomenon." She argued for a Wittgensteinian, "nonsuperlative" re-consideration of the role of conceptual systems, situating them in our language-infused human practices rather than anywhere else. As a result, novel metaphor can only be observed against the background of specific and concrete contexts of language use.

For the cognitive researcher, there does not seem to be an issue here of choosing for or against Wittgenstein. Instead, Martins' argument throws into relief how the approach to language and thought as cognitive systems is not sufficient for a sophisticated view of the actual workings of metaphor during use. What is needed is a further refinement of these system-oriented approaches, according to whether the systems are seen as either abstract, theoretical constructs, which are studied in their own right by cognitive linguists; social constructs carried by groups or cultures, which are studied by anthropologists or cultural sociologists; or individual constructs put to use by real people in their concrete human practices (e.g. Gibbs 1999c). As with the notions of literal and metaphorical discussed above, philosophical work on language and thought as systems can be made productive for theoretical modeling in the service of empirical research.

\subsection{Language as system}

When we turn from the philosophical papers to the cognitive-scientific papers presenting work on metaphor in language as a system, the distance with the applied-linguistic work on metaphor is diminished. For our present purposes, these are examples of papers that address an aspect of the status quo in one approach, language as system. This status quo regarding language as system is necessarily assumed and placed in the background 
as provisionally unproblematic by the applied linguist who is interested in metaphor in language as use. Of course, these "language-as-system" papers pursue their own ends in terms of their own traditions. But for the applied linguist who adopts a cognitive approach to metaphor, these are papers representing a different approach to metaphor, functioning as an auxiliary in the applied linguistic research.

We may now illustrate one of the benefits of this attempt to order the field of cognitive research on metaphor. In accepting that applied linguists take on board a set of assumptions about work done on metaphor in language as system, it becomes clear that such metaphor research is embedded in linguistic traditions of their own. For instance, when we look at the papers by Margarida Basilio and Heronides Moura, applied linguists need to come to terms with a model of the language system that can accommodate the relations between metaphor in morphology (Basilio) and metaphor in the lexicon (Moura). The selection of such a model is not unproblematic. By implication, it is important for applied linguists to be explicit about what they are taking on board for the temporary purpose of their investigation, and what not.

Let us take Moura's paper as a case in point. His work on polysemy in the lexicon is situated in the generative tradition represented by Pustejovsky (1995). This model works with rather elaborate representations of lexical items, including accounts of their argument structure, event structure, qualia structure, and lexical inheritance structure. Moura's main point is that this "richer lexical representation would make it possible for the semantic theory to describe the creative use of words, including regular polysemy and metonymy." And it is not just that "regular polysemy is predictable from the lexicon's structure", but it is "predictable from the lexicon's structure only, regardless of a previous cognitive process" (my emphasis, GS).

The basic question asked by Moura concerns the role of the lexicon as an independent contributor to the creation of meaning. He contrasts this to the more important role assigned to the encyclopedia in the cognitivelinguistic approach. However, what is facilitated by the adoption of a more neutral bird's eye view of all these approaches is to raise the question of the concrete and precise relation between the two approaches.

In particular, the generativist view highlights meaning as produced by the lexical system of the dictionary, whereas the cognitive-linguistic 
view highlights meaning as produced by the conceptual system of the encyclopedia. I hasten to add that these are all too blatant generalizations in themselves, as may be understood from the exchange between Taylor (1996) and Jackendoff (1996; cf. 2002). However, what is at issue is Moura's argument "that the linguistic system has a role in the production of figurative meanings, and that this role is associated with systematic lexical relations, ..." I would prefer to see this as one possible hypothesis. If regular polysemy is held to follow from the lexicon's structure only, this view follows from a set of initial assumptions about the role of the lexicon that differs from the assumptions of at least some cognitive linguists, such as Taylor. A bird's eye view of the cognitive approaches to metaphor, however, raises the question why the generative account of the lexicon could not alternatively be developed to account for the conceptual system, to the effect that it is not words but concepts that display the kind of structure or information postulated by Pustejovsky. Another question would ask why the two systems, linguistic and conceptual, could not work in concert, instead of attributing all responsibility for the creation of meaning to the linguistic system. In fact, this turns out to be Moura's position, too, who wishes to see the lexicon as a constraint on conceptual metaphor (personal communication, 7 March 2003). Applied linguists who favor the cognitivelinguistic approach might prefer a view of language in which the lexicon has a more limited role to play, and if they do, they should not incorporate Moura's view of the lexicon in their own view of language as system without further ado.

The adoption of the more specific standpoint of the applied linguist who starts out from language as use raises another question. How are the linguistic and conceptual systems as reconstructed by Moura (or Taylor) involved in the "creative use of words" as understood by the applied linguist, the discourse analyst, the pragmatician, and many cognitive linguists? Only if there is perfect correspondence between the structure of the abstract lexicon of the ideal native speaker on the one hand and the individuals' lexical repertoires on the other, can it be claimed that the structure of the lexicon as proposed by Moura directly accounts for the creation of meaning in concrete use. This is an assumption that not many psycholinguists and psychologists would be prepared to make.

These questions are of equal importance for the study of the lexical constructions discussed by Margarida Basilio. She analyzes swordfish and 
beija-flor as metaphorical compounds, the former depending on an image mapping between the form of a sword and the form of a fish, while the latter is slightly more complex. The compound beija-flor can be glossed as "kiss-flower", and means "humming bird". The claim is that there is a metaphorical mapping between the relation between the humming bird and a flower on the one hand and one person kissing another person on the other hand. My question about this type of analysis would be whether the mapping perceived as relevant for language as a morphological or lexical system should also be invoked for the analysis of language as use or thought as use. In other words, how plausible would it be to claim that these mappings are part of language use defined in some psychological manner? Do language users always retrieve or construct these linguistic or conceptual mappings in their minds when they lexically access these words? And how can this be determined? The distinction between the two approaches raises questions about metaphor in language and thought that require further empirical and theoretical research.

Let me finally explicate the connection with applied linguistics. Under what view of applied linguistics would it be interesting to have to deal with the metaphorical mapping detected in beija-flor? Well, it might be interesting for developing teaching programs in second or foreign language learning. But does it require an applied linguist to find and describe this type of mapping? Or does it make more sense that this type of metaphorical meaning is more relevant to a description of language as a system, which is then assumed as part of the input for the curriculum? I prefer the latter view of the division of labor, because it is eventually the general systematicity in the language system that decides how an expression will be presented for learning in education. Findings from a language as system approach are needed or presupposed by the applied linguist who then wishes to include them into a language teaching program that may be studied as language as use.

The relation between the perspective on language as system and language and thought as use is also important for the paper on blending by Maria Salomão. In fact she also includes the fourth approach, which deals with cognition as conceptual system, and discusses a number of metaphors in a typically cognitive-linguistic mix of all four approaches. That is, she makes assumptions about language as system and use, and about thought as system and use, and produces an argument based on all 
of these assumptions. In this case, Salomão concludes that blending theory may be a better candidate for dealing with novel metaphor than conceptual metaphor theory (cf. Grady, Oakley, and Coulson 1999).

My problem with this kind of mixed approach is that so many assumptions are made for so many approaches at the same time. For instance, to turn to the "thought-as-system" approach that is part of Salomão's project, how secure is the postulation of conceptual metaphors like LIFE IS A JOURNEY? Lakoff and Johnson (1999) have recently adopted the distinction between primary and complex metaphor advanced by Grady (1997). LIFE IS A JOURNEY is a complex metaphor that may be analyzed as arising through the combination of a number of primary metaphors, including PURPOSES ARE DESTINATIONS. However, it is one thing to claim that our conceptual system has primary metaphors which may be combined to produce complex metaphors during use, but it is another claim to state that our conceptual system has both primary as well as complex metaphors in conventionalized and fixed forms. At this moment, it seems to me that we simply know too little to make either assumption at the exclusion of the other or even further alternatives (cf. Murphy 1996, 1997; Vervaeke and Kennedy 1996). Moreover, when we shift the perspective from these systems to cognitive processing, it is not necessarily the case that the analyses offered by blending theorists actually capture what is going on in the minds of individual language users (Gibbs 1999c; 2000). It is therefore important to be explicit about which assumptions from which approach are accepted when a judgment has to be made regarding the overall conclusion of the paper that conceptual metaphor theory cannot deal with novel metaphor as well as blending theory. Focusing on one approach while backgrounding the others seems to be a research strategy that makes this type of monitoring of assumptions more manageable. It temporarily fixes a status quo in one or more alternative approaches while critically examining the claims of one provisionally central approach.

\subsection{Language as use}

Cognitive linguists often focus on all four approaches at the same time, but applied linguists regularly combine two out of four in that they typically address language and thought as use. Apart from Lynne Cameron's series of workshops on metaphor-led discourse analysis, this combination of 
approaches was also evident from the papers by João Telles on (teacher) counseling and Maria Isabel Asperti Nardi on librarian training. Both Telles and Nardi address thought processes through the careful analysis of language use, but they also pay attention to language awareness and other aspects of language use as opposed to thought process.

The relation between approaching metaphor as part of language as use versus as part of thought as the use of a conceptual system is also important for Cameron's work. Her metaphor-led discourse analysis produces a list of expressions that qualify as metaphorical talk. However, Cameron is careful not to make unwarranted inferences about the presumably related metaphorical thought processes. If cognitive linguists have a tendency to see the linguistic patterns as evidence for underlying conceptual processes, applied linguists like Cameron are more skeptical or perhaps neutral about these postulated connections and ask for further validation (cf. Low 1999).

Cameron's approach to language as use is socio-cultural. Her approach to language as use is from one specific vantagepoint, namely as the process of interaction between individuals engaged in the discourse. A broad indication of this type of approach might be interactional sociolinguistics or conversation analysis of the kind represented by Gumperz, Schegloff, and others, although I am not sure whether Cameron would like to call herself that. My point is that this particular type of approach looks at language as use by focusing on the interaction patterns in the behavior of the language users. That is the decisive framework which facilitates Cameron's analysis of metaphorically used words as, for instance, "stepping stones" in an educational setting, or as "a rope bridge flung across a gorge" of affective distance between a perpetrator and a victim in a criminal setting. That is also the framework for deciding how metaphors in the language can be taken as indications of perspectives and attitudes of speakers, which is strictly speaking a matter of metaphor as thought. Cameron is aware of this and is careful to use the wording "metaphors suggest perspectives and attitudes": she remains true to her language as use approach, and the relation with thought as the use of a conceptual system is only one of possible implications for further research.

Another way in which Cameron is careful is in her alignment with a competing definition with language as use, which I would like to call, for want of a better term, the "textual" approach to language as use. This 
concerns the conceptualization of language use as a semiotic structure that exceeds the level of the sentence, and has to do with the analysis of relational, referential and topical coherence, discourse type, discourse form, and discourse content. These phenomena are all studied by Cameron from her interactional or socio-cultural perspective, and this perspective affects how observations are made about these textual aspects of metaphor in language use. For instance, it is not just observed that metaphors occur at the end of an episode of talk, but it is also observed that they function as summaries. Moreover, this is an observation that accords with previous findings of other interactional sociolinguists (e.g. Drew and Holt 1998), so that the interpretation of this phenomenon seems to have relatively high validity. When Cameron finds other textual patterns that are relatively novel in the metaphor literature, she is careful to hedge her conclusions by stating, for instance, that "There may be patterns in the dynamics of Topic and Vehicle utterances in episodes around metaphors." In my opinion, this displays a high level of sensitivity to the nature and limitations of the application of one perspective (the interactional one) to these data. It rightly alerts us to the need for further research in this area, with other data and with another perspective on language as use (the textual one), before any firm conclusions about this aspect of metaphor in language as use may be drawn.

Moving on to other plenary applied-linguistic paper at the conference, there is Nardi's research on the interpretation, by a number of librarian trainees, of the metaphor industrialists of information. This paper takes us into the approach of metaphor as part of thought, and more specifically, thought as the use of a conceptual system. The first phase of Nardi's study is concerned with each student's process of metaphor comprehension and interpretation (Gibbs 1994), and she uses individual verbal protocols to track these cognitive processes (cf. Steen 1994; Cameron 2002).

What is interesting is that the procedure then involves a shift, from eliciting individual text processing to guiding the socially negotiated interpretation of the metaphor by the same subjects in an event of group reading. These are two rather different moments in the study. The first involves language use as a backgrounded and expressive medium of metaphorical thought, and may be seen as concerned with the process of metaphor interpretation. The second moment places language use much more in the foreground, as a constitutive interactional tool between students for understanding their own thought, while trying to construct a more 
detailed collaborative interpretation of the metaphor. Labeling this interaction process as "the socioconstruction of the interpretation of the target metaphor," in my view, is only applicable to the second phase: the first phase involves the participants' individual interpretation of the target metaphor and may be seen as a cognitive psychological study.

Nardi also points out the implications of the group interpretation of the target metaphor in students' understanding of their emergent model of the practice of librarianship. She affords insight into one moment of the process of understanding and constructing a detailed model of the future librarians ' practice and of a new professional identity and self-image. The result of this process, a professional's completed self-image, is the main target of João Telles's study of a secondary school teacher's notions of teaching and language. He addresses the story of his participant about her development as a teacher, and interprets her story as a variant of the awakening of sleeping beauty.

My emphasis on the distinction between language as use versus thought as use may be helpful here in that it facilitates dealing with the tenacious relation between the teacher's words in the interviews on the one hand (language use) and the sleeping beauty theme behind the words that is reconstructed by the analyst on the other hand (thought as use). Since this connection is not self-evident, one may think of conducting further interviews which can clarify whether the participant does indeed see herself as a sleeping beauty who has awakened, and if so, in what respects, precisely. The distinction between approaches might make it easier to accept that further interviewing entails taking a step back from the original verbal data (language as use), which might otherwise remain the center of interest for an applied-linguistic study of this teacher's metaphors. Another differentiation that might follow from the proposed distinctions is the one between this self-image as a retrospective reconstruction of a personal past as opposed to this self-image as data about the genuine development itself. The latter could only be achieved if there were previous verbal protocols, through which the development of the story of sleeping beauty might be traced in a longitudinal fashion.

Tony Berber's work, finally, on metaphor in early applied linguistics writing, starts at the opposite end of the scale. It starts out with patterns of metaphorical usage in a large corpus of written texts, and thereby backgrounds the thought that may lie behind any single incidence of a 
potentially metaphorical collocation. Instead, Berber aims to find recurrent possible underlying metaphors, which means that he is addressing conventional metaphor in the lexicon. If anything, his study lies on the border between language as use and language as system.

Apart from suggesting metaphorical senses for key lexical items, Berber's work also suggests conventional metaphorical mappings, such as TEACHING IS CONSTRUCTION. The latter need to be tested for their validity in independent research on metaphor in conceptual systems, with the appropriate theories and methodology of this approach. This is precisely what ought to be done with all of the conventional metaphors proposed by cognitive linguistics, and this is precisely why the above-mentioned distinction between the four approaches is needed.

\section{Conclusion}

I have tried to show how the various general papers at the conference adopt different positions towards finding metaphor in language and thought. Some stop short of doing the actual empirical research and present philosophically fundamental queries regarding the theoretical conceptualization of the whole undertaking (Rajagopalan and Martins). I have argued that applied linguists need to remain aware of these issues, but should not hesitate in proceeding to formulate their own theoretical and operational standpoints for research.

Others emphasize that metaphor can also be approached as part of language regarded as a symbolic system, with such distinct levels of linguistic organization as morphology and the lexicon (Moura and Basilio). These research traditions, I have claimed, often come with their own assumptions about the role of language as a system during language use and cognitive process. It is not always unproblematic to adopt the findings or approaches of these traditions into a research project utilizing another approach, such as language as use. Therefore it takes some caution in deciding which aspects of these approaches to language as system should be taken on board in an applied linguistics project. However, at the same time, applied linguists cannot do without such assumptions about the language system, so that they are simply forced to make a choice about their language as system assumptions at some point. 
The same holds true for assumptions about thought as a conceptual system, and thought as the use of that conceptual system during cognitive processing. We have seen how the findings of these approaches do play a role in applied linguistic research of various kinds, with reference to work by Cameron, Telles, Nardi, and Berber. My main point here has been to insist that most of the findings of applied linguists concern language as use. Such findings may allow for formulating implications for thought as use or language and thought as system, but these implications are tentative. They are hypotheses for further research that should be pursued within the framework of these alternative approaches themselves.

I wish to close this paper with a reference to the one plenary paper that I have not mentioned. Jacob Mey suggested that metaphors should not merely be approached as arising from language or thought and then taken as influences on our activities and environment. He proposed that we should turn this perspective round. Mey sees metaphors as pragmatic acts, or types of activities that have a special effect on our understanding. My own attitude to this proposal is that this may say something about the origin of some metaphors, but that it still requires or at least does not preempt an analysis of the cognitive and linguistic effects of these activities along the lines that I have suggested. It is true that a fully behavioral orientation to metaphor and the ways it is expressed demands attention to pragmatic acts, but it is also true that pragmatic acts cannot be accounted for solely from a social or interactional perspective. Therefore I should like to stick to the importance of the four approaches distinguished in this paper as the more central starting points for any study of metaphor in language and thought.

\section{Author's note}

I am grateful to Mauricio Carvalho, Heronides Moura, and Solange Vereza for their useful comments and suggestions.

E-mail: gj.steen@let.vu.nl 


\section{REFERENCES}

Cameron, L. 1999a. Operationalising 'metaphor' for applied linguistic research. In L. Cameron \& G. Low (Eds.), Researching and applying metaphor (pp. 3-28). Cambridge: Cambridge University Press.

1999b. Identifying and describing metaphor in spoken discourse data. In L. CAMERON \& G. Low (Eds.), Researching and applying metaphor (pp. 105-132). Cambridge: Cambridge University Press.

CAmeron, L. 2002. Metaphor in educational discourse. London and New York: Continuum.

\& Low, G. 1999. Metaphor. Language Teaching, 32, 77-96.

\& Low, G. (Eds.). 1999. Researching and applying metaphor. Cambridge: Cambridge University Press.

Drew, P., \& Holt, E. 1998. Figures of speech: figurative expressions and the management of topic transition in conversation. Language in society, $27,495-522$.

Fauconnier, G., \& Turner, M. 2002. The way we think: Conceptual blending and the mind's hidden complexities. New York: Basic Books.

GeeraerTs, D. 1997. Diachronic prototype semantics: A contribution to historical lexicology. Oxford: Oxford University Press.

Gibbs, R. W., jr. 1993. Process and products in making sense of tropes. In A. Ortony (Ed.), Metaphor and thought, second edition (pp. 252-276). Cambridge: Cambridge University Press. . 1994. The poetics of mind: figurative thought, language, and understanding. Cambridge: Cambridge University Press. 1999a. Intentions in the experience of meaning. Cambridge: Cambridge University Press.

. 1999b. Researching metaphor. In L. CAMERon \& G. Low (Eds.), Researching and applying metaphor (pp. 29-47). Cambridge: Cambridge University Press

.1999c. Taking metaphor out of our heads and putting it into the cultural world. In R. W. Gibbs, jr. \& G. J. Steen (Eds.), Metaphor in cognitive linguistics (pp. 145-166). Amsterdam: John Benjamins.

. 2000. Making good psychology out of blending theory. Cognitive Linguistics, 11(3/4), 347-358.

GluCKSBERG, S. 2002. Understanding figurative language. New York: Oxford University Press. 
Glucksberg, S., \& Keysar, B. 1993. How metaphors work. In A. Ortony (Ed.), Metaphor and thought, second edition (second ed., pp. 401-424). Cambridge: Cambridge University Press.

Grady, J. E. 1997. Foundations of meaning: Primary metaphors and primary scenes. Unpublished Ph D, University of California, Berkeley, Berkeley. , OAKLEY, T., \& Coulson, S. 1999. Blending and metaphor. In R. W. GibBs, jr. \& G. J. Steen (Eds.), Metaphor in cognitive linguistics (pp. 101-124). Amsterdam: John Benjamins.

JACKendoff, R. 1996. Conceptual semantics and cognitive linguistics. Cognitive Linguistics, 7(1), 93-129.

2002. Foundations of language: Brain, meaning, grammar, evolution. Oxford: Oxford University Press.

Lakoff, G. 1986. The meanings of literal. Metaphor and Symbolic Activity, 1(4), 291-296.

1993. The contemporary theory of metaphor. In A. OrTONY (Ed.), Metaphor and thought (second ed., pp. 202-251). Cambridge: Cambridge University Press.

1994. What is a conceptual system? In W. F. Overton \& D. S. Palermo (Eds.), The nature and ontogenesis of meaning (pp. 41-90). Hillsdale, NJ: Lawrence Erlbaum. \& Johnson, M. 1980. Metaphors we live by. Chicago: Chicago University Press.

\& Johnson, M. 1999. Philosophy in the flesh: The embodied mind and its challenge to western thought. New York: Basic Books.

Low, G. 1999. Validating metaphor research projects. In L. CAMERon \& G. Low (Eds.), Researching and applying metaphor (pp. 48-65). Cambridge: Cambridge University Press.

\& Cameron, L. 2002. Applied-linguistic comments on the metaphor identification project. Language and Literature, 11(1), 84-90.

Murphy, G. 1996. On metaphoric representation. Cognition, 60, 173-204. . 1997. Reasons to doubt the present evidence for metaphoric representation. Cognition, 62, 99-108.

Pustejovsky, J. 1995. The generative lexicon. Cambridge, MA: MIT Press.

Schiffrin, D., Tannen, D., \& Hamilton, H. E. (Eds.). 2001. The handbook of discourse analysis. Oxford: Blackwell.

STEEN, G. J. 1994. Understanding metaphor in literature: an empirical approach. London: Longman. 
1999. Genres of discourse and the definition of literature. Discourse Processes, 28(2), 109-120.

2001. A rhetoric of metaphor: linguistic and conceptual metaphor and the psychology of literature. In D. H. Schram \& G. J. Steen (Eds.), The Psychology and Sociology of Literature: In Honor of Elrud Ibsch (Vol. 35, pp. 145-164). Amsterdam: John Benjamins.

. 2002a. Metaphor in Bob Dylan's 'Hurricane': Genre, language, and style. In E. Semino \& J. Culpepper (Eds.), Cognitive stylistics: language and cognition in text analysis (pp. 183-210). Amsterdam: John Benjamins.

. 2002b. Poetics and linguistics again: the role of genre. In S. CsABI \& J. Zerkowitz (Eds.), Textual secrets: the message of the medium (pp. $42-$ 51). Budapest: School of English and American Studies, Eotvos Lorand University Budapest. 386-407.

2002c. Metaphor identification: A cognitive approach. Style, 36(3),

(Ed.). (In press). Researching and applying metaphor across languages. Special issue of Journal of Pragmatics.

\& GibBs, R. W., jr. 1999. Introduction. In R. W. GibBs, jr. \& G. J. Steen (Eds.), Metaphor in Cognitive Linguistics (pp. 1-8). Amsterdam: John Benjamins.

\& GibBs, R. W., jr. (In preparation). Finding metaphor in language and thought. Amsterdam: John Benjamins.

TAYLOR, J. 1996. On running and jogging. Cognitive Linguistics, 7(1).

Vervaeke, J., \& Kennedy, J. M. 1996. Metaphors in language and thought: Falsification and multiple meanings. Metaphor and Symbol, 11(4), 273284. 